\title{
Síndrome de Gorlin-Goltz - relato de caso
}

Gorlin-Goltz syndrome - case report

Síndrome de Gorlin Goltz - reporte de caso

Virgílio Bernardino Ferraz Jardim

ORCID: https://orcid.org/0000-0001-5462-1599

Universidade de Pernambuco, Brasil

E-mail: virgilioferraz84@hotmail.com

Allan Vinícius Martins de Barros

ORCID: https://orcid.org/0000-0002-5818-1575

Universidade de Pernambuco, Brasil

E-mail: allanmartinsodonto@gmail.com

Rafaella Amorim Bittencourt Maranhão de Araújo

ORCID: https://orcid.org/0000-0001-7796-4578

Universidade de Pernambuco, Brasil

E-mail: rafaellabma@ hotmail.com

Lucas Viana Silva Ramos

ORCID: https://orcid.org/0000-0002-5818-1575

Universidade Federal de Pernambuco, Brasil

E-mail: lucaaschin@gmail.com

Luiz Fernando Alves de Lima

ORCID: https://orcid.org/0000-0002-5515-3261

Universidade Federal de Pernambuco, Brasil

E-mail: luizlimafernando@hotmail.com

Emanuel Dias de Oliveira e Silva

ORCID: https://orcid.org/0000-0002-7482-7815

Universidade de Pernambuco, Brasil

E-mail: residenciactbmf@upe.br

\begin{abstract}
Resumo
Introdução: A síndrome de Gorlin-Goltz é também denominada de síndrome do nevo basocelular ou síndrome do carcinoma nevóide de células basais. Esta é uma rara desordem hereditária autossômica dominante, causada pela mutação no gene supressor de tumor PTCH1. Relato de caso: Paciente do gênero masculino, 15 anos de idade, procurou o serviço de Cirurgia e Traumatologia Buco-Maxilo-Facial, relatando dores discretas na região retromolar direita, sendo solicitada uma ortopantomografia, notando-se a presença de 1 lesão na maxila e 2 lesões na mandíbula (esquerda e direita), todas associadas a dentes impactados. Na investigação, encontrou-se calcificação da foice cerebral, pontificação da sela túrcica, e depressões na região plantar dos pés. Foi realizada a enucleação e curetagem das lesões maxilares e remoção dos dentes impactados. Ao exame histopatológico, foi diagnosticado Ceratocisto Odontogênico. Discussão: A SGG consiste em um transtorno neurocutâneo, que se manifesta principalmente em pacientes jovens, sem predileção por gênero. Kimonis et Al (1997) determinam uma forma de diagnóstico através da presença de critérios maiores e critérios menores. No caso relatado foi encontrado três critérios maiores e um critério menor. Conclui-se, portanto, que apesar dos diversos achados para diagnóstico, o de maior relevância para o cirurgião Buco-Maxilo-Facial são os ceratocistos, tendo um alto poder de recidiva e destruição, estando presente em $70 \%$ dos casos de SGG, sendo mais frequente na mandíbula e associado a dentes inclusos. Até o momento, o diagnóstico e tratamento do caso mencionado foi satisfatório, fazendo-se necessário também um acompanhamento multiprofissional.
\end{abstract}

Palavras-chave: Síndrome de Gorlin-Goltz; Ceratocisto odontogênico; Cistos odontogênicos.

\begin{abstract}
Introduction: Gorlin-Goltz syndrome is also referred to as basal cell nevus syndrome or basal cell nevoid carcinoma syndrome. This is a rare autosomal dominant inherited disorder caused by mutation in the PTCH1 tumor suppressor gene. Case report: A 15-year-old male patient sought the Maxillofacial Surgery service, reporting mild pain in the right retromolar region, and an orthopantomography was requested, noting the presence 1 maxillary injury and 2 mandible injuries (left and right), all associated with impacted teeth. In the investigation, we found calcification of the cerebral scythe, pontification of the turgical saddle, and depressions in the sole of the feet. Enucleation and curettage of maxillary lesions and removal of impacted teeth were performed. At histopathological examination, Odontogenic Keratocyst was diagnosed. Discussion: SGG is a neurocutaneous disorder that manifests mainly in young patients without gender preference. Kimonis et Al (1997) determine a form of diagnosis by the presence of larger and smaller
\end{abstract}


criteria. In the reported case, three major and one minor criteria were found. It is concluded, therefore, that despite the several diagnostic findings, the most relevant for the maxillofacial surgeon are the keratocysts, which have a high recurrence and destruction power, being present in $70 \%$ of the SGG cases. more frequent in the jaw and associated with teeth included. So far, the diagnosis and treatment of the case mentioned has been satisfactory, and a multidisciplinary follow-up is also required.

Keywords: Gorlin-Goltz syndrome; Odontogenic keratocyst; Basal cell carcinoma.

\section{Resumen}

Introducción: El síndrome de Gorlin-Goltz también se denomina síndrome de nevo de células basales o síndrome de carcinoma nevoide de células basales. Se trata de un trastorno hereditario autosómico dominante poco común, causado por la mutación en el gen supresor de tumores PTCH1. Caso clínico: Paciente masculino de 15 años que acude al servicio de Cirugía y Traumatología Buco-Maxilofacial, refiriendo dolor leve en región retromolar derecha, solicitando ortopantomografía, constatando la presencia lesión en el maxilar y lesiones en la mandíbula, todas asociadas con dientes retenidos. En la investigación se encontró calcificación de la hoz cerebral, pontificación de la montura turca y depresiones en la región plantar de los pies. Se realizó la enucleación y legrado de las lesiones maxilares y la extracción de los dientes retenidos. El examen histopatológico reveló un queratoquiste odontogénico. Discusión: SGG consiste en un trastorno neurocutáneo, que se manifiesta principalmente en pacientes jóvenes, sin predilección de género. Kimonis et al (1997) determinan una forma de diagnóstico mediante la presencia de criterios mayores y menores. En el caso reportado, se encontraron tres criterios mayores y un criterio menor. Se concluye, por tanto, que a pesar de los diversos hallazgos diagnósticos, los más relevantes para el cirujano buccomaxilofacial son los queratoquistes, que tienen un alto poder de recurrencia y destrucción, estando presentes en el $70 \%$ de los casos de SGG, siendo más frecuente en la mandíbula y asociado a dientes incluidos. Hasta el momento, el diagnóstico y tratamiento del caso mencionado ha sido satisfactorio, requiriendo un seguimiento multiprofesional.

Palabras clave: Síndrome de Gorlin-Goltz; Queratoquiste odontogénico; Quistes odontogénicos.

\section{Introdução}

O primeiro relato associado à Síndrome de Gorlin-Goltz (SGG) foi realizado no antigo Egito, onde um esqueleto foi encontrado com lesões nos maxilares, semelhantes a cistos odontogênicos, costelas bífidas e alterações nos metacarpos (Fuji \& Mayashita, 2014).

A SGG, também chamada Síndrome do Carcinoma Nevóide de Células Basais ou Síndrome do Nevo Basocelular, foi descrita primariamente por Jarish e White, em 1894. Porém, suas manifestações clínicas na forma de síndrome foram detalhadas apenas em 1960, por Robert J. Gorlin e Robert W. Goltz, pesquisadores que dão nome à atual síndrome. Gorlin e Goltz descreveram a tríade clássica da síndrome: múltiplos Carcinomas Basocelulares (CBC), múltiplos ceratocistos e costelas bífidas (Kuhn-Dall'magro, 2014).

Este quadro consiste em um transtorno neurocutâneo, hereditário, autossômico dominante, com penetrância incompleta e expressão variável, que se manifesta principalmente em pacientes jovens e sem predileção pelo gênero (Linares, Montagne, Suarez, Simon, Garcia, \& Rivero, 2018).

A SGG está associada à mutação do gene patched 1 (PTCH1), um gene supressor de tumor localizado no cromossomo 9 (9q22, 3-q31). Entretanto, 15 a 27\% dos casos não apresentam mutação detectável. Na atualidade, não se compreende perfeitamente a correlação genótipo-fenótipo. A taxa de prevalência da síndrome varia entre 1: 31.000 até 1: 256.000 (Huq, Bogwitz, Gorelik, Winship, White, \& Trainer, 2017; Linares, Montagne, Suarez, Simon, Garcia, \& Rivero, 2018; Rehefeldterne, et al., 2016).

Dentre os sinais clássicos da síndrome, os primeiros a surgirem são as alterações esqueléticas, como as costelas bífidas e a macrocefalia, que tem início ainda na formação intrauterina associada ao começo da osteogênese. Dentre outros achados que surgem precocemente, destacam-se os ceratocistos odontogênicos que, com frequência, surgem antes dos 10 anos de vida (Fuji \& Mayashita, 2014).

Entre a puberdade e a terceira idade surgem os primeiros CBCs, principal característica da síndrome, identificados em até $90 \%$ dos casos (Souza, Ormay, D'elia, Correia, \& Silva, 2016).

Outras neoplasias como meduloblastomas, meningiomas, fibromas cardíacos e ovarianos, apesar de menos frequentes, 
podem se apresentar nos pacientes sindrômicos (Souza, Ormay, D'elia, Correia, \& Silva, 2016).

Nos dias atuais, o principal algoritmo utilizado para diagnóstico é o proposto por Kimonis et al (1997), onde critérios maiores e menores foram listados. Para o fechamento do diagnóstico a presença de pelo menos dois critérios maiores ou a associação entre um critério maior e dois critérios menores são necessários.

Um dos critérios maiores e, comumente, um dos primeiros achados clínicos a serem encontrados são os ceratocistos odontogênicos. A apresentação sindrômica dessas lesões é um desafio na rotina do cirurgião bucomaxilofacial, em função da capacidade de recidiva dessas lesões, bem como da sua multiplicidade.

A primeira descrição dos ceratocistos foi realizada por Philipsen em 1956 sob o nome "Queratocisto Odontogênico". Porém, foi descrito com detalhes histológicos apenas em 1970 e 1971 com as publicações de Browne. Este autor detalhou características histológicas importantes, bem como a sua alta capacidade de recidiva (Noy, Rachmiel, Zar, Emodi, \& Nagler, 2017).

Sabe-se que o ceratocisto tem origem histológica dos restos celulares da lâmina dentária. Este cisto, diferentemente de outras entidades císticas, parece ter seu crescimento associado tanto a pressão osmótica como a fatores enzimáticos ligados a própria parede cística, fatos que levaram a ser considerado como uma lesão neoplásica até um passado recente (Noy, Rachmiel, Zar, Emodi, \& Nagler, 2017).

Nesse sentido, este trabalho tem como objetivo relatar e discutir o caso de um paciente acometido por múltiplos ceratocistos odontogênicos e portador da SGG.

\section{Metodologia}

Trata-se de um estudo de caso de característica qualitativa e descritiva. De acordo com Pereira et al. (2018), pesquisas desta natureza caracterizam-se por elucidar um determinado assunto e estudá-lo minuciosamente. A investigação consta descrições das análises clínicas, imaginológicas e laboratoriais, bem como a terapêutica empregada e subsequente prognóstico do paciente acometido pela síndrome do Carcinoma Nevoide Basocelular.

\section{Relato de caso}

Paciente do gênero masculino, 15 anos de idade, procurou o serviço de Cirurgia e Traumatologia Buco-Maxilo-Facial do Hospital Universitário Oswaldo Cruz - Recife-PE, para investigação clínica e tratamento cirúrgico de múltiplas lesões císticas nos maxilares.

$\mathrm{Na}$ consulta inicial o paciente relatou que sentia dores discretas localizadas principalmente na região retromolar direita, fato este que motivou a solicitação de uma ortopantomografia.

No exame inicial, notou-se presença de três lesões radiolúcidas extensas localizadas na maxila e na mandíbula. Na região maxilar esquerda foi notada uma lesão unicística extensa, expansiva por todo seio maxilar esquerdo, medindo cerca de 5 $\mathrm{cm}$ em seu maior diâmetro e relacionada ao terceiro molar superior ipslateral. Na região retromolar esquerda observou-se uma lesão radiolúcida multilocular com aproximadamente $3,5 \mathrm{~cm}$ de extensão, associada à impactação do terceiro molar inferior esquerdo. Na região retromolar direita encontrava-se uma lesão radiolúcida multilocular, em conjunto aos terceiro e segundo molares impactados pelo cisto, estendendo-se da região de corpo posterior de mandíbula até a região de ramo mandibular direito (Figura 1).

Figura 1 - Radiografia panorâmica inicial. São observadas lesões em região retromolar direita, retromolar esquerda e região de seio maxilar esquerdo. 
Research, Society and Development, v. 10, n. 2, e49610210476, 2021

(CC BY 4.0) | ISSN 2525-3409 | DOI: http://dx.doi.org/10.33448/rsd-v10i2.10476

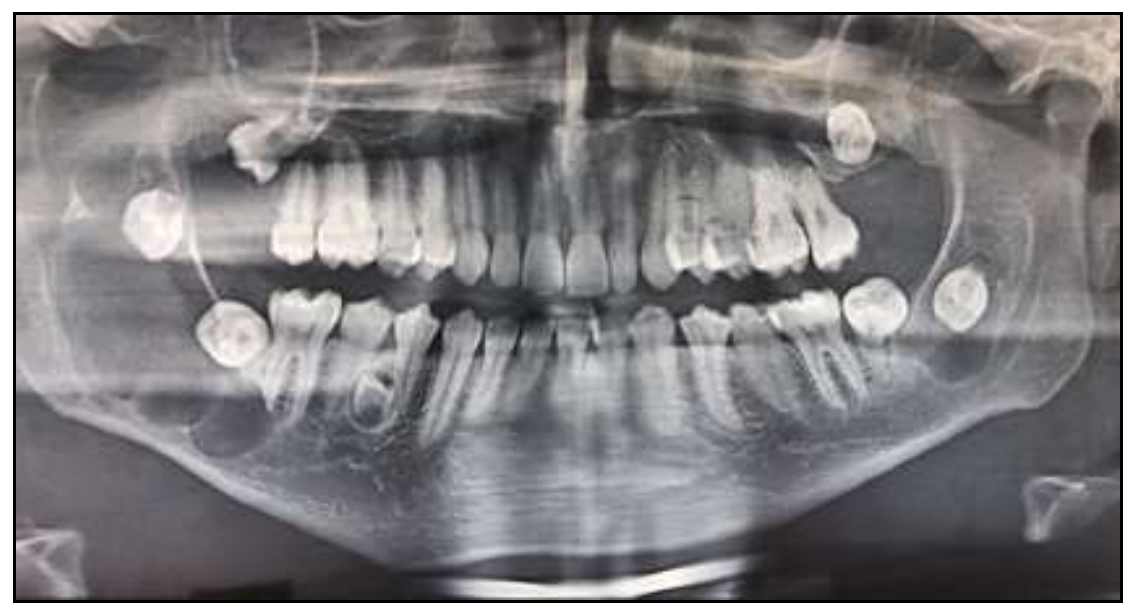

Fonte: Autores (2020).

Ao exame tomográfico do tipo feixe cônico, pode-se notar a natureza cística das lesões, bem como sua capacidade de destruição do trabeculado ósseo (Figura 2A, 2B e 2C).

Figura 2A- Aspecto tomográfico da lesão em mandíbula direita; Figura 2B - Lesão em mandíbula esquerda; Figura 2C-Lesão maxilar.

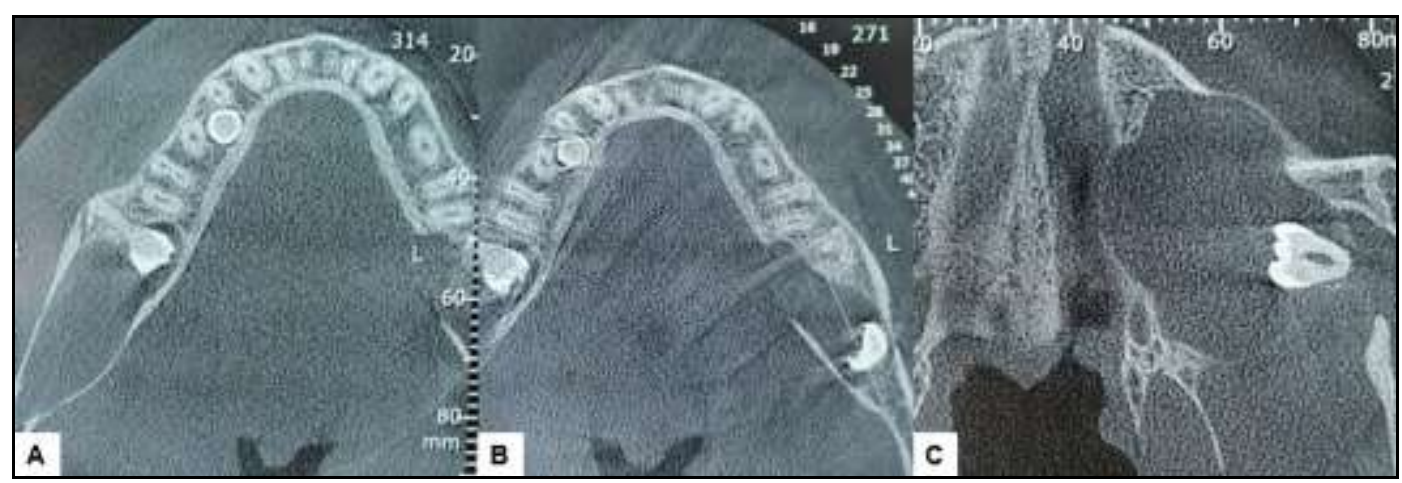

Fonte: Autores (2020).

Ainda antes do procedimento cirúrgico/diagnóstico, se procedeu com investigação clínica para possível correlação das lesões císticas com outras alterações sistêmicas ou síndromes.

Realizaram-se exames de imagem para investigação de possíveis alterações em região torácica e craniana. Nenhum achado radiográfico relevante foi encontrado na radiografia do tórax, entretanto, tanto a tomografia computadorizada (Figura 3C) quanto a radiografia póstero-anterior de crânio (Figura 3A) evidenciaram uma região hiperdensa e radiopaca, respectivamente, na região mediana do crânio, compatível com calcificação da foice cerebral. Na radiografia de perfil de crânio (Figura 3B) nota-se também a pontificação da sela túrcica.

No exame minucioso do tegumento, observaram-se pequenas depressões na região plantar dos pés (Figura 4). O paciente relatou que, sazonalmente, as depressões apareciam na palma das mãos, porém, durante o acompanhamento, não se pode notar tal achado. 
Figura 3A - PA de Crânio evidenciando calcificação da foice cerebral; Figura 3B - Radiografia em Perfil demonstrando a pontificação da sela túrcica; Figura 3C - Tomografia Computadorizada externando a calcificação da foice cerebral.

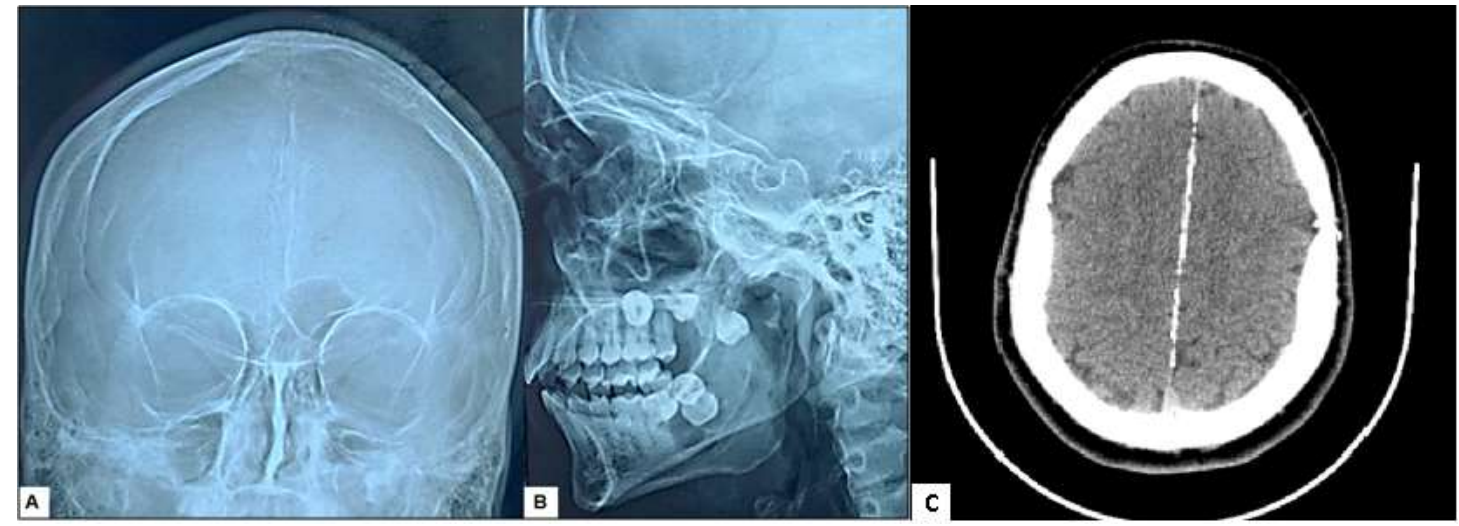

Fonte: Autores (2020).

Figura 4 - Depressões plantares indicadas pelas setas amarelas.

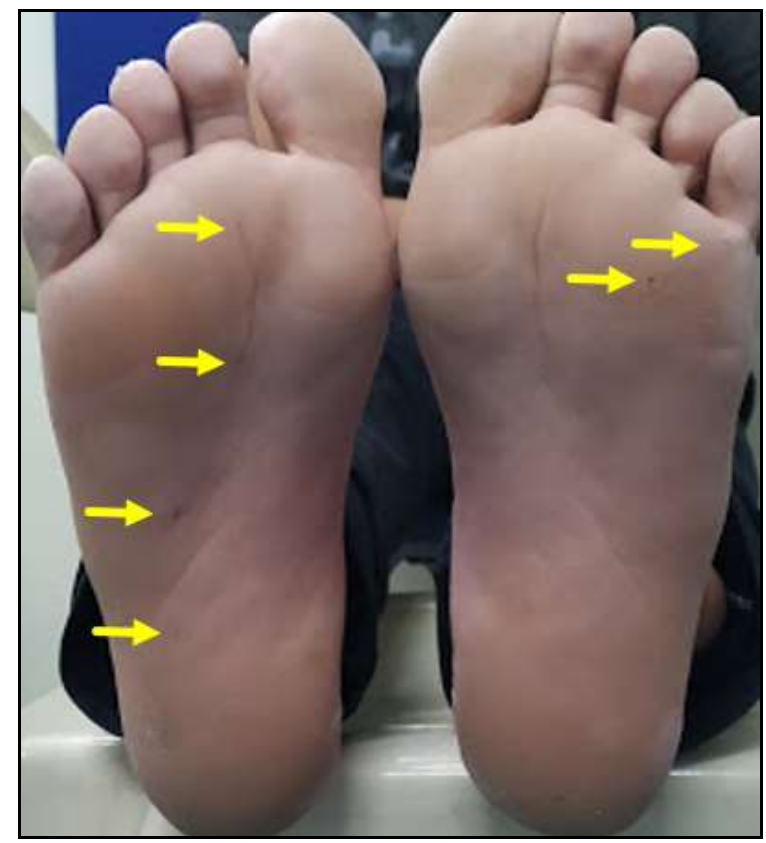

Fonte: Autores (2020).

Ainda, verificou-se no dorso nasal uma depressão cicatricial circular com cerca de $1 \mathrm{~cm}$. O paciente relatou que a cicatriz seria consequência de múltiplos procedimentos para remoção de lesão recidivante, sem, no entanto saber precisar qual o diagnóstico histopatológico da lesão.

A abordagem utilizada para a terapêutica consistiu na enucleação e curetagem das lesões maxilares, tendo em vista os achados clínicos e radiográficos.

O procedimento cirúrgico foi realizado sob anestesia geral, onde se realizou punção aspirativa que evidenciou a presença de material caseoso semi-sólido no interior das lesões. Procedeu-se com enucleação cuidadosa das lesões e curetagens das paredes ósseas. Os dentes impactados associados foram removidos em conjunto com as lesões. Cirurgicamente, notou-se a presença de capsula fibrosa com conteúdo pastoso de coloração leitosa. O material seguiu para exame histopatológico. (Figura $5 \mathrm{~A}$ e $5 \mathrm{~B})$. 
Research, Society and Development, v. 10, n. 2, e49610210476, 2021

(CC BY 4.0) | ISSN 2525-3409 | DOI: http://dx.doi.org/10.33448/rsd-v10i2.10476

Figura 5A - Aspecto transcirúrgico da remoção da lesão em região retromolar esquerda; Figura 5B - Peça cirúrgica após enucleação.

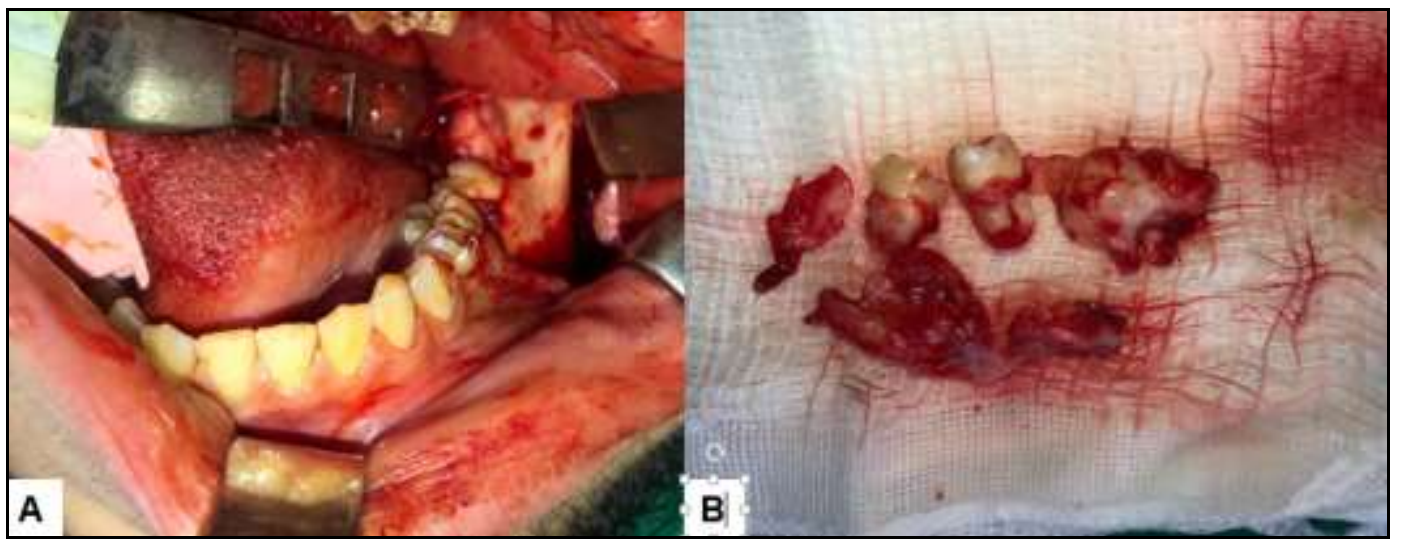

Fonte: Autores (2020).

Os cortes histológicos corados em Hematoxilina e Eosina de todas as amostras consistiram em lesão cística com revestimento epitelial delgado, envolta por cápsula de tecido conjuntivo fibroso associado à ausência de infiltrado inflamatório. O epitélio se caracterizou como pavimentoso estratificado paraqueratinizado de aspecto corrugado, com camada basal epitelial composta por células colunares hipercromáticas em paliçada. O diagnóstico histopatológico final foi de múltiplos ceratocistos odontogênicos (Figura 6). Estudo imunohistoquímico evidenciou expressão de BCL-2 positiva em queratinocitos basais e fibroblastos estromais, Ki-67 positiva fraca (>10\%) em camada basal do epitélio, p63 positiva em epitélio (Figura 7) e p53 negativa.

Figura 6 - Aspecto histológico da lesão em fotomicrografia em menor (100x) e maior aumento (400x). Coloração da lâmina em Hematoxilina e Eosina (HE).

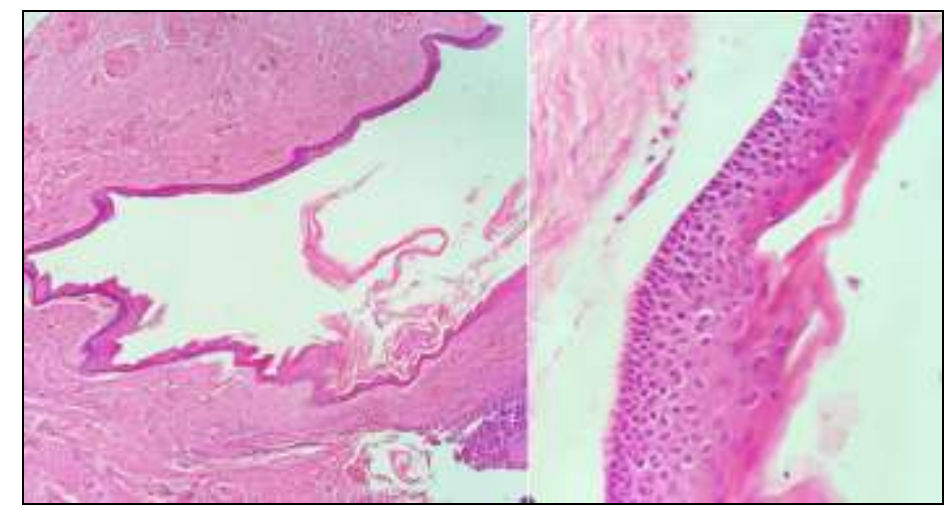

Fonte: Autores (2020). 
Research, Society and Development, v. 10, n. 2, e49610210476, 2021

(CC BY 4.0) | ISSN 2525-3409 | DOI: http://dx.doi.org/10.33448/rsd-v10i2.10476

Figura 7 - Estudo imunohistoquímico evidenciando expressão de BCL-2 positiva em queratinocitos basais e fibroblastos estromais e p63 positiva em epitélio.

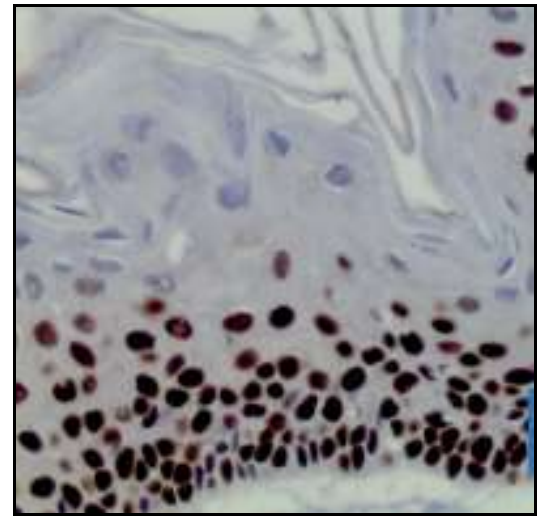

Fonte: Autores (2020).

Tendo em vista os aspectos clínicos citados, entendemos que são compatíveis com uma expressão da Síndrome de Gorlin-Goltz de acordo com a diagrama proposto por Kimonis et al (1997).

Atualmente, o paciente encontra-se com quinze meses de acompanhamento pós operatório sem queixas ou sinais de recidiva (Figura 8$)$.

Figura 8 - Reconstrução Tomográfica 3D - Acompanhamento tomográfico de 15 meses sem evolução das lesões.

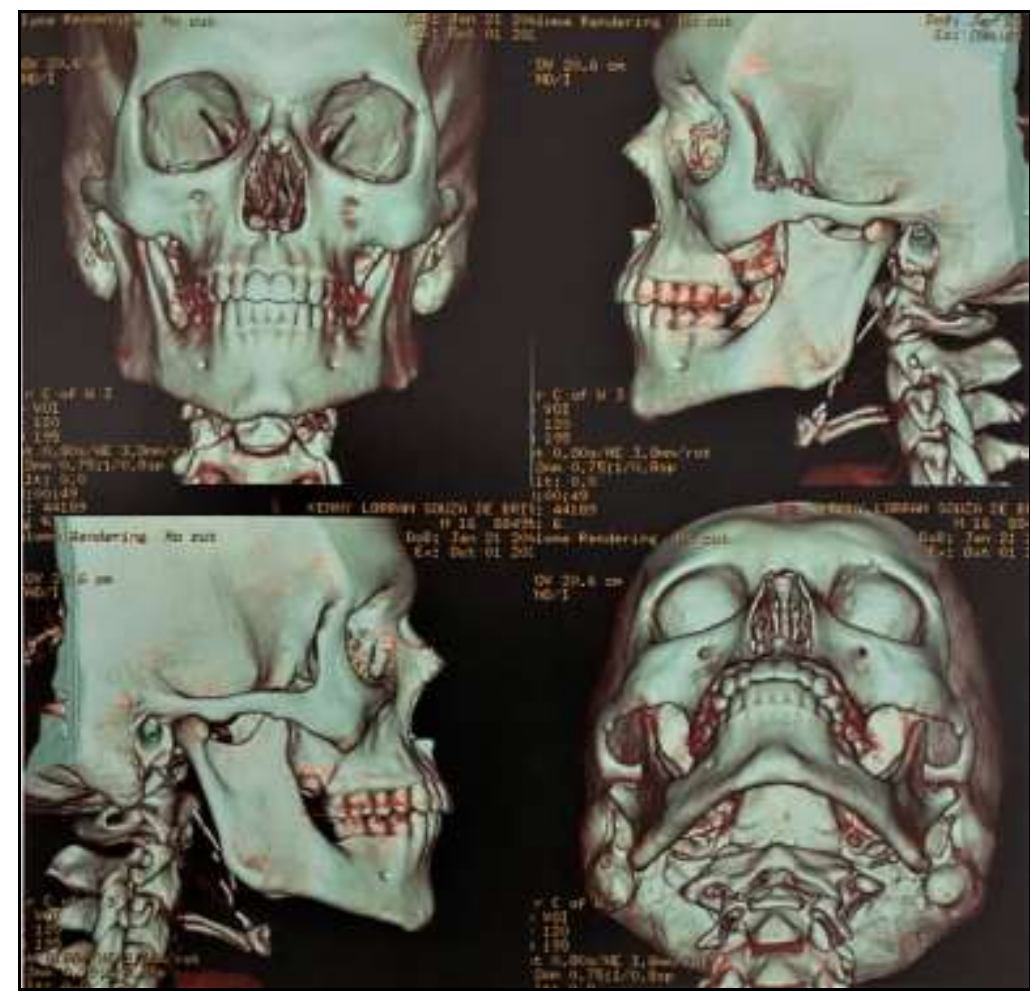

Fonte: Autores (2020).

\section{Discussão}

A SGG é caracterizada como um transtorno neurocutâneo, que se manifesta principalmente em pacientes jovens sem predileção pelo gênero. Sua tríade clássica consiste na presença de Carcinomas Basocelulares, Ceratocistos odontogênicos e 
costelas bífidas (Kuhn-Dall'magro, 2014). O caso clínico relatado é condizente com os achados da literatura, tendo em vista que o paciente se encontra na segunda década de vida.

O diagnóstico da SGG é sempre desafiador, pois as principais características da síndrome podem aparecer em diferentes períodos da vida. Assim, esta deve fazer diagnóstico diferencial com o Xeroderma Pigmentoso, Síndrome de Christol Bzex-Dupre, a ingestão de arsênio e do próprio Carcinoma Basocelular (Linares, Montagne, Suarez, Simon, Garcia, \& Rivero, 2018).

Nos poucos estudos epidemiológicos relatados, percebe-se que a expectativa de vida dos pacientes sindrômicos é discretamente menor que a população em geral. Apenas $19 \%$ dos óbitos nos pacientes sindrômicos têm relação direta com os sinais da síndrome. Entretanto, nota-se que os enfermos têm um impacto negativo na qualidade de vida, seja pelas consequências diretas dos sinais sindrômicos ou dos seus tratamentos (Rehefeldt-erne, et al., 2016).

Os múltiplos $\mathrm{CBCs}$, as alterações no sistema esquelético, como escolioses, a necessidade de múltiplas intervenções cirúrgicas e quimioterapia podem ser considerados fatores que reduzem significativamente o bem-estar (Huq, Gorelik, Winship, White \& Trainer, 2017).

No caso relatado não notamos alteração significativa da qualidade de vida descrita pelo paciente. Entretanto, entendemos as diversas consultas de acompanhamento especializado, tanto para controle do tratamento cirúrgico realizado, como para diagnóstico precoce de possíveis lesões, podem ser um fator de dificuldade social, considerando que o paciente reside remotamente ao centro médico especializado em que é acompanhado.

Kimonis et al (1997) determinaram uma forma de diagnóstico através da presença de critérios maiores e critérios menores. Assim, para o diagnóstico é necessário a presença de dois critérios maiores ou um critério maior em conjunto com dois critérios menores (Kimonis, et al., 1997) (Tabela 1).

Tabela 1 - Critérios diagnósticos (Kimonis et al, 1997).

\section{CRITÉRIOS MAIORES CRITÉRIOS MENORES}

\begin{tabular}{l|l}
\hline $\begin{array}{l}\text { Mais de dois carcinomas basocelulares ou } \\
\text { um antes dos } 20 \text { anos. }\end{array}$ & $\begin{array}{l}\text { Alterações radiológicas: Pontificação da sela túrcica, } \\
\text { anormalidades vertebrais como hemivértebras, fusão } \\
\text { ou alongamento de corpos vertebrais, defeitos das } \\
\text { mãos e pés, lucências em chama de vela nos ossos } \\
\text { das mãos }\end{array}$ \\
\hline Ceratocistos Odontogênicos & $\begin{array}{l}\text { Malformações congênitas: fenda labial/palatina, } \\
\text { hipertelorismo, bossa frontal }\end{array}$ \\
\hline Três ou mais depressões palmo-plantares & $\begin{array}{l}\text { Alterações esqueléticas: deformidade de Sprengel, } \\
\text { sindactilia, pectus escavatum }\end{array}$ \\
\hline Calcificação da foice cerebral & Macrocefalia \\
\hline Costelas bífidas, fundidas ou achatadas & Meduloblastoma \\
\hline Parente em primeiro grau com a síndrome & Fibroma ovariano \\
\hline
\end{tabular}

Fonte: Autores (2020). 
Os critérios maiores são: dois ou mais carcinomas basocelulares ou um em idade inferior a 20 anos, presença de ceratocisto odontogênicos, três ou mais depressões palmo-plantares, calcificação da foice cerebral, costelas bífidas, fundidas ou achatadas e familiares em primeiro grau com SGG. Os critérios menores são: macrocefalia, más formações congênitas como: bossas frontais, fenda labial ou palatina, hipertelorismo, anomalias esqueléticas (deformidade de Sprengel, peito deformado, hemivértebras, fusão ou alongamento de corpos vertebrais, defeitos das mãos e dos pés, sindactilia, cistos ósseos nas mãos, pontificação da sela túrcica), fibroma ovariano e meduloblastoma (Kimonis, et al., 1997).

No caso relatado, os critérios maiores encontrados foram os ceratocistos odontogênicos, encontrados em três localizações diferentes nos maxilares, as depressões na região plantar dos pés, calcificação da foice cerebral. Dentre os critérios menores encontrou-se a pontificação da sela túrcica, totalizando assim, três critérios maiores e um critério menor.

Vale ressaltar que o paciente relatou remoção de uma lesão ulcerada na região de dorso nasal, que foi executada ainda na infância sem a realização de exame histopatológico. Não podemos descartar e nem comprovar que a referida lesão tenha sido um CBC.

O presente estudo se assemelha aos casos relatados na série de sete casos apresentada por Roson-Gomez et al (2009). Os autores encontraram como principal achado clínico o CBC (85,7\%). Todos os casos foram encontrados lesões na região da face. O segundo achado mais frequente foram os ceratocistos odontogênicos com 71,4\%. A calcificação da foice cerebral representou $57,1 \%$. As depressões palmo-plantares constituíram $42,8 \%$, alterações esqueléticas $42,8 \%$ e pontificação na sela túrcica 28,5\% (Gomez, Garcia, Gias, Perez, Guerra, \& Gonzalez, 2009).

As depressões palmo-plantares são achados clínicos característicos da síndrome e de fácil identificação a nível ambulatorial. Apresentam-se como pequenas pontuações na região das palmas das mãos e planta dos pés, que em análise histológica apresentam-se como hipoceratose, hiperplasia das células basais dispostas em paliçada e presença de sangue nos vasos da derme capilar (Fuji \& Mayashita, 2014).

Segundo Fujji e Miyashita (2014), a calcificação da foice cerebral está presente em cerca de $65 \%$ indivíduos portadores da SGG, sendo um achado radiológico importante para o diagnóstico. Na juventude a calcificação da foice pode não ser detectada, porém, com o envelhecimento e aumento da calcificação, pode ser mais fácil a detecção radiográfica (Fuji \& Mayashita, 2014).

Apesar dos diversos achados clínicos possíveis no diagnóstico da síndrome, o de maior relevância para o Cirurgião Bucomaxilofacial são os ceratocistos. Estas lesões podem aparecer de forma múltipla, com grande poder de destruição óssea e alta capacidade de recidiva.

O ceratocisto está presente em cerca de $70 \%$ dos casos de SGG. São mais frequentes na mandíbula e podem estar associados a dentes inclusos (Gomez, Garcia, Gias, Perez, Guerra, \& Gonzalez, 2009). No caso relatado, todas as lesões císticas apresentavam dentes inclusos associados.

A técnica mais utilizada no tratamento das lesões císticas é a enucleação. Está pode ser pouco efetiva quando utilizada de forma isolada, o que faz com técnicas adjuvantes como ostectomia periférica, crioterapia e cauterização química com solução de Carnoy sejam indicadas em conjunto para reduzir a taxa de recorrência (Kuhn-Dall'magro, 2014).

O ceratocisto é considerado uma lesão cística com alto poder de recidiva. Somado a isto, sabe-se que a taxa de recidiva das lesões associadas à SGG podem chegar até 63\% (Kuhn-Dall'magro, 2014). (Gomez, Garcia, Gias, Perez, Guerra, \& Gonzalez, 2009).

Noy et al (2017) fizeram um estudo comparativo entre os ceratocistos esporádicos e os sindrômicos. Os autores analisaram retrospectivamente 102 cistos, dos quais 32 acometeram pacientes portadores da síndrome. A taxa de recidiva foi maior nos ceratocistos sindrômicos (47\%) do que nos esporádicos (20\%) (Noy, Rachmiel, Zar, Emodi, \& Nagler, 2017).

A taxa de recidiva é maior nos pacientes sindrômicos, mesmo que tratamentos mais agressivos sejam utilizados. 
Dessa maneira, concordamos com Rosón-Gómez et al (2009), que afirma que para pacientes jovens o tratamento dos ceratocistos deve ser o mais conservador possível.

Para Kim et al (2017), as formas mais agressivas de tratamento incluindo a ressecção cirúrgica são sempre mais efetivas. Entretanto, em pacientes jovens as ressecções ocasionariam alterações severas de desenvolvimento dentário e ósseo (Kim, Oh, Seo, Kim, Nam, \& Lim, 2017).

Dessa maneira, optamos como primeira alternativa cirúrgica uma abordagem conservadora, com enucleação das lesões císticas e remoção dos dentes inclusos associados. Nesse caso, a enucleação foi satisfatória por se tratar de uma primeira intervenção cirúrgica de cunho diagnóstico e por permitir a possibilidade de um tratamento preservador, sem mutilações para o paciente.

\section{Conclusão}

A Síndrome de Gorlin-Goltz é um distúrbio neurocutâneo raro e que requer atenção especial por parte do Cirurgião Buco-Maxilo-Facial, devendo este profissional participar ativamente do diagnóstico e tratamento dessa síndrome.

É essencial a atuação frente aos ceratocistos, que apesar de serem lesões císticas, têm alto poder de recidiva e destruição.

O paciente segue em acompanhamento pos-operatório de 15 meses, sem queixas associadas e sem sinais de recidivas das lesões.

Para investigações futuras é sugerido pesquisas que aperfeiçoem o diagnóstico precoce da síndrome de Gorlin-Goltz, uma vez que as lesões císticas maxilo-mandibulares podem causar defeitos estéticos e funcionais importantes. Desse modo, é imprescindível um diagnóstico ágil e precoce para intervir antes ou em fases iniciais das lesões, possibilitando menores sequelas e danos ao paciente.

\section{Referências}

Fuji, K., \& Mayashita, T. (2014). Gorlin Goltz syndrome (nevoid basal cell carcinoma syndrome): Updateand literature review. Pediatr Int, 56, $667-674$.

Gomez, S. R., Garcia, R. G., Gias, L. N., Perez, J. S., Guerra, M. F., \& Gonzalez, F. J. (2009). Síndrome de Gorlin-Goltz: serie de 7 casos. Rev Esp Cir Oral Maxilofac, 31(5), 309-315.

Huq, A. J., Bogwit, M., Gorelik, A., Winship, I. M., White, S. M., \& Trainer, A. H. (2017). Cohort study of Gorlin syndrome with emphasis on standardised phenotyping and quality of life assessment. Intern Med J, 47(6), 664-673.

John, A. M., \& Schwartz, R. A. (2016). Basal cell naevus syndrome an update on genetics. Br J Dermatol, 174(1), 68-76.

Kim, S. H., Oh, M. S., Seo, Y. S., Kim, J. Y., Nam, S. H., \& Lim, S. M. (2017). Conservative Treatment of Multiple Keratocystic Odontogenic Tumors in a Young Patient with Nevoid Basal Cell Carcinoma Syndrome by Decompression: A 7-year Follow-up Study. J Clin Pediatr Dent, 41 (4), 300-304.

Kimonis, V. E., Goldstein, A. M., Pastakia, B., Yang, M. L., Kase, R., Digiovanna, J. J., et al. (1997). Clinical manifestations in 105 persons with nevoid basal cell carcinoma syndrome. Am J Med Genet, 69(3), 299-308.

Kuhn-Dall'magro, A. (2014). Síndrome de Gorlin-Goltz - relato de casos. RFO, 19(2), 239-244.

Linares, V. S., Montagne, R. D., Suarez, J. P., Simon, M. R., Garcia, C. P., \& Rivero, I. B. (2018). Síndrome de Gorlin Goltz. A propósito de un caso. Gac med espirit, 20(3), 136-145.

Noy, D., Rachmiel, A., Zar, K., Emodi, O., \& Nagler, R. M. (2017). Sporadic versus syndromic keratocysts-Can we predict treatment outcome? A review of 102 cysts. Oral Dis, 23(8), 1058-1065.

Pereira, A. S., Shitsuka, D. M., Parreira, F. J., \& Shitsuka, R. (2018). Metodologia da pesquisa científica. [e-book]. Santa Maria. Ed. UAB/NTE/UFSM. https://repositorio. ufsm. br/bitstream/handle/1/15824/Lic_Computacao_MetodologiaPesquisa-Cientifica. Pdf.

Rehefeldt-erne, S., Nageli, M. C., Winterton, N., Felderer, L., Weiber, L., Hafner, J., et al. (2016). Nevoid Basal Cell Carcinoma Syndrome: Report from the Zurich Nevoid Basal Cell Carcinoma Syndrome Cohort. Dermatology, 232(3), 285-292.

Souza, G. H., Ormay, M. S., D'elia, M. L., Correia, P. S., \& Silva, S. C. (2016). Síndrome de Gorlin-Goltz - Relato de Dois Casos. Revista SPDV, 74(4), 391394. 